\title{
Will we have enough to eat in the near future? What the Brazilian Society of Plant Physiology and The Global Plant Council have to do with it?
}

\author{
Gustavo Habermann ${ }^{1 *}$, Ricardo Bressan-Smith²
}

'Departamento de Botânica, Instituto de Biologia, Universidade Estadual Paulista "Júlio de Mesquita Fiho", Rio Claro, SP, Brazil.

2Plant Physiology Laboratory, Universidade Estadual do Norte Fluminense Darcy Ribeiro, Campos dos Goytacazes, RJ, Brazil.

*Corresponding author: ghaber@rc.unesp.br

Received: 22 October 2013; Accepted: 20 January 2014

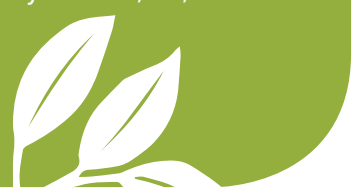

It was not until 2012 that I have heard about the Global Plant Council, or GPC. In 2011, I was elected the $13^{\text {th }}$ President of the Brazilian Society of Plant Physiology (BSPP), and the board of members and I had to re-think and modernize this scientific society that used to be remembered only in even years, because of the national Congress of the BSPP. The Brazilian Journal of Plant Physiology (BJPP) had already experienced memorable times, when it was supposedly prepared to be indexed by JCR/ISI, but this journal was, in 2011, going through a difficult situation and needed to be "shaken". Then, the BJPP was renamed Theoretical and Experimental Plant Physiology (TxPP), and a contract with Springer was signed. This worldwide publisher will be responsible for disseminating $\mathrm{TxPP}$ in 2014. It was under those circumstances that I was told by the $12^{\text {th }}$ President of the BSPP, Professor Ricardo Bressan-Smith, that I should go to the annual meeting of the GPC.

But what is the GPC, what is it for, and why should I go to South Korea, having to travel overseas for more than 48 hours? "What will be discussed there", I asked, at the beginning of 2012 .

Little by little, I was exposed to e-mail exchanges between GPC members. Then I was invited to give a short speech at that event (GPC 2012), and it should fit the food security theme. Why food security?

\section{FOOD SECURITY}

In my speech at that meeting, I defended initiatives for investigating genes of native species, whose functions are still unknown (Souza and Habermann 2012). Specifically, I showed that many woody plants native to the Brazilian savanna, which is locally named Cerrado (meaning closed vegetation), are able to grow on soils that are acidic and rich in aluminum ( $\mathrm{Al})$, and that some species of Vochysiaceae and Melastomataceae families accumulate more than 10,000 $\mathrm{g}$ of $\mathrm{Al}$ per leaf dry mass (Haridasan 2008). However, crop species suffer great damages from edaphic Al toxicity, mainly in the tropics and subtropics, and symptoms can be observed in root (Kopittke et al. 2008) and aerial systems, with serious consequences for their metabolism (Horst et al. 2010). Between 30 and $45 \%$ of the ice-free land area in the world have soils that can be considered acidic and rich in $\mathrm{Al}$ (von Uexküll and Mutert 1995), depending on the range of soil $\mathrm{pH}$ to be considered. Therefore, given this scenario, why not investigating these native plants in order to understand their $\mathrm{Al}$ metabolism and Al-related genes? After all, these species have been growing on these acidic soils from Cerrado areas for more than 60 millions years (Pinheiro and Monteiro 2010). But agronomists also consider $\mathrm{Al}$ toxicity to be partially resolved, as lime $\left(\mathrm{CaCO}_{3}\right.$ and $\left.\mathrm{MgCO}_{3}\right)$ application reduces $\mathrm{Al}$ in the soil, increases soil base saturation and elevates the $\mathrm{pH}$ in the soil. However, lime application costs US\$ 350 per hectare and it must be applied every year (Ratter et al. 1997). In addition, as agricultural frontiers have advanced into Cerrado areas in Central Brazil since 1960, man has neglected this native vegetation and has consistently replaced this landscape with agriculture (soybean, cotton and sugar cane) and pasture 
(Sawyer 2008). In this way, how many new genes and unknown metabolisms as well as metabolites have been ignored and abandoned? Millions of years of evolution totally thrown away! The removal of the Cerrado vegetation since 1960 has certainly improved yields, especially on an area based solution. But within the next 40 years, the world will need to increase crop yields dramatically and, thus, Cerrado and Amazonia will, again, face pressures for more land for agriculture. That was my speech in South Korea (Habermann 2012).

But food security is more complex than that. While people and the media are still concerned about global warming and atmospheric $\mathrm{CO}_{2}$ rising, food security is a silent threat and it will be sensed within the next 20-40 years to come.

One might remember the 2008 riots in many countries because of crop shortages and high food prices, especially prices of rice (Gruissem et al. 2012). This is a small snapshot of what may happen in the future. The Food and Agriculture Organization of the United Nations (FAO) describes that today around one billion people suffer from starvation and many more are malnourished (http://www.fao.org/hunger/en/). In this way, population growth, climate change, soil degrading, desertification, increase in pest and disease pressures for crops, among other factors, will cause deep consequences for food security, for developing and developed countries. In 2050, there likely will be 9 billion people living on Earth, and there are many predictions that food production will not increase in the same pace.

Until the middle of the 1990s, agricultural production grew satisfactorily, providing the world population with enough food and survival resources, including energy and oil. At those times, people started talking about food quality, such as "green" and "organic" production, and food security or threat of starvation was an unusual speech. That satisfactory food production was achieved mostly by the so-called "green revolution", in which the use of improved cultivars, vigorous genotypes, irrigation, application of pesticides and fertilizers was the new way of performing agriculture (Kush 2001). This model of food production has worked out until recently, and it is based on a premise of maximum efficiency to be withdrawn from crops, using the maximum energy and natural resources available at any cost. Many achievements on yields have been obtained through the use of modern grain genotypes with increased sunlight penetration into the canopy, because of steep leaf angles on plants with short stems and great nitrogen use efficiency and, if possible, high resistance to lodging, all preferably included into an early maturity plant cycle. Norman Borlaug (1914-2009), the only agronomist ever laureate by the Sweden Academy of Sciences, may be remembered forever due to his contributions to the green revolution.
Notwithstanding, these biotechnological resources, which were named by Fuglie et al. (2012) as "input intensification", were also evidenced by the same authors to have declined since the 1960s. According to these authors, irrigation and area expansion stayed more or less constant throughout the years, and the input intensification has fallen sharply. More recently, global crop yield averages are also declining. Between 1920 and 1960, the increase rates of yield $(\mathrm{t} / \mathrm{ha})$ for maize, wheat and rice were approximately 0.69 , 0.99 , and $0.49 \%$, respectively. These rates increased to 1.73 , 2.57 and $2.19 \%$ for the same crops between 1960 and 1990, thanks to the green revolution. But between 1990 and 2008, maize yield increase rate was around $1.78 \%$; for wheat, it was $0.97 \%$ and, for rice, $1.07 \%$, clearly indicating a saturation on increase gains, or even a possible decline (Pardey, PG University of Minnesota). Accordingly, relative prices of many primary commodities have increased sharply since around 2000 (Pfaffenzeller et al. 2007). Therefore, there is much evidence showing that we have reached a period in which agronomic science has encountered difficulties to surpass the current yield indexes, as global population and hunger pressure is at the door.

In 2008, Brazil was "accused" of subsidizing sugarcane plantations, instead of providing farmers with a more appropriate policy for food production. Certainly, some countries, accompanied by the media, wanted to blame on someone else for those rises in commodity prices, especially rice. However, in the case of Brazil, sugarcane has been planted where pasture, rather than crops, used to grow. In São Paulo state, for instance, sugarcane plantations have advanced into citrus groves, due to advantageous economical reasons (Nogueira 2013).

On the other hand, policies performed by developed, developing and transition countries clearly demonstrate that well-succeeded nations in agriculture, which exhibit high yield indexes, are those that have long invested in research and development (Fuglie et al. 2012), being yield indexes highly variable between and within countries, especially continental countries, such as Russia, Brazil, USA, Australia, China and India. But we should always remember that the maintenance of good yield indexes as presented today would not suffice to overcome threatens on food security within the next $20-40$ years. Crop yields must increase beyond the current indexes to meet food demands of world's population.

Today, we depend on ten major species to provide $95 \%$ of our food, and currently, around one billion people suffer from starvation; if yield indexes are kept the same as today's yields, by 2050 we will need to produce 50 to $70 \%$ more food (Koning and Lttersum 2009). In addition, approximately $40 \%$ of arable 
soils are acidic, high in aluminum and low in fertility, and when water use efficiency is considered, we all should know that it takes one ton of water to produce one kilogram of wheat or rice (http://globalplantcouncil.org/home).

In order to tackle the above-mentioned challenges, there are two basic possibilities: (i) increasing yields potentials of major crops or (ii) pushing expansion of agriculture into native vegetation areas, which would be disastrous to the environment and for the biodiversity conservation.

Rising yields from $50 \%$ to $70 \%$ of its current yield indexes requires novel solution in plant science for controlling biotic and abiotic stresses. One possibility would be improving plant metabolic efficiencies, shifting $\mathrm{C}_{3}$ crops to $\mathrm{C}_{4}$ crops. This strategy seems to be already feasible, such as the well-known example in rice (Hibberd et al.2008), and protocols for such metabolic challenge seem to be widely discussed in the scientific community (Leegood 2013). Regarding the use of biomass, there are predictions suggesting that it will be economically realistic to produce biofuel from cellulose, rather than carbohydrates, in the near future (Hill et al. 2006, Sawyer 2008). However, although safe biotechnology to produce biofuel from cellulose may indicate high efficiency of energy conversion, on the other hand, according to Sawyer (2008) it may also represent a concentration of biofuel production taking place on lands closer to markets, including marginal land not suited for grains or cane. This could become (i) an incentive to people to explore any type of cellulose, including native vegetation, which would represent a regression on biodiversity conservation and also (ii) an economical motivation to farmers for investing on cellulose production, rather than food.

Therefore, there are tools to be accessed and it certainly implies the use of transgenic techniques and release of new and more productive genotypes. Genetically modified organisms (GMO) are not usually accepted by people or countries, and it has always been a polemic issue (Davison 2010, Chen and Lin 2013). However, transgenic techniques are the best biotechnology tools we have in hands to propose solutions, such as controlling biotic and abiotic stresses, changing metabolism, and also manipulating conversion of energy in photosynthetic and microbiological processes. Thus, if there will not be an worldwide acceptance of transgenic plants, we are likely to end up advancing into new areas of native vegetation to explore lands necessary to enhance crop yields on an area based solution. Cropland in tropical countries (Africa, Tropical Asia, Oceania and South America), which includes Brazil, has expanded by $48,000 \mathrm{~km}^{2}$ per year, from 1999 to 2008 , and major native vegetation already replaced by croplands are grasslands, savannas and moist broadleaf forests, such as the
Amazonian forest (Phalan et al. 2013). An interesting case is the Cerrado in Brazil, which has become an important agriculture frontier since 1960. Until recently, Cerrado areas used to be considered "unfit for farming", mainly because of the low soil fertility, with high concentration of $\mathrm{Al}$ and low $\mathrm{pH}$ in the soil. But fertilization and lime application has provided conditions for performing agriculture on these lands (Souza and Habermann 2012). In this direction, the annual area deforested for agriculture in the Cerrado is on a par with that in the Amazon (Lapola et al. 2010). Therefore, despite the undeniable contribution of Cerrado areas to Brazilian crop yields since the 1960s, we cannot allow further devastation of this biome, together with the Amazonian forest, at the cost of feeding the world, using a "technology" of the last century, such as land expansion.

\section{WHAT IS THE GLOBAL PLANT COUNCIL?}

The Global Plant Council, or GPC (http://globalplantcouncil. org/home), was born in 2009, during the annual meeting of the American Society of Plant Biology, in Hawaii, USA. During the meeting, 16 plant science organizations and societies worldwide endorsed the "idea" of the GPC. As a general concept, the GPC deploys the experience of plant science societies to find solutions to the problems that threaten the humankind — problems that take into account the plant sciences. As pointed out, some sorts of relevant concerns are overwhelming governments and institutions in the last 10 years: The pressure for rising up the food supplies, along with nutrition quality, the renewable energy and plant-based feedstocks are turning to a red alert since official estimates reveal that around nine or ten billion people will be living on earth by 2050 (Taiz 2013). And worse, when one considers that the mentioned urgent necessities meet the necessities for solving the agricultural sustainability and climate change, the problem enhances.

When GPC was formed, Dr. Mel Oliver (University of Columbia, USA) gathered important plant scientists and scientific societies in Hawaii, in 2009. The concept of the GPC had been launched, and the following meeting in Montreal, Canada, in 2010, was pertinent to define the rules and aims. By transcribing the text (available at the GPC official website), the aims designed by the joint initiatives of the scientists and organizations involved, were:

- Increase awareness of the central importance of plant science.

- Accelerate progress in solving pressing global problems via plant science based approaches.

- Facilitate new research programs to address global challenges.

- Enable more effective use of knowledge and resources.

- Provide a focus and contact point for plant science across the globe. 
As priority, GPC efforts might be able to identify and coordinate strategic solutions to the current global challenges, focusing on five priority areas, as Sustainable Intensification of Crop Production, Adaptation to a Changing Climate, Transition to a Green Economy, Food Security and Health and Exchange of Knowledge, Data and Resources. Such discussed priorities among all the member organizations and societies allowed the GPC to identify initiatives within each of its priority areas and to provide plant-based solutions to current global problems via strategic research programs, provide a focus for member organizations to work together, help to disseminate knowledge and expertise, strengthen current interactions and establish new collaborations, and also increase the profile of GPC at the international level.

In 2011, the annual meeting was held in Qingdao, China, which was relevant for the establishment of the strategies for the coming years. In an intensive two-day working, 15 delegates decided that the best way forward was to generate two-page proposals to hold workshops on key issues related to global challenges and to seek funding for them. These workshops would bring together plant scientists, breeders and other specialists from all over the globe with the necessary expertise to generate a road map as to how plant science can address, mitigate, or offer solutions for the issues that GPC planned to address. In addition, the Council identified nine key issues that GPC felt should be discussed and facilitated in the global plant community in greater depths. These nine key issues, in order of perceived priority for GPC action, were:

1. Digital Seed Bank - to provide a stable perpetuation of crop genetic diversity for future generations, initially focusing on those crops that provide most of the calories for the world food supply, by creating a digital database of genome sequences, phenotypic information, expression data, proteome and metabolome assessments etc. that would be open to all breeders and scientists and would supplement physical long-term seed storage.

2. Local-level Diversity and Yield Stability - to provide a means by which breeding efforts targeted to specific environmental conditions, utilizing local germplasm that is being characterized around the world, can be facilitated and enhanced in the public sector.

3. Increasing/Enriching Agricultural Diversity - to promote the deployment of underutilized seed and root crops and cropping systems that might have nutritional and environmental benefits, as well as a return to the farmers that are growing them.

4. Biofortification - to advocate for the development of new and existing crops that are more nutritious so that people receive the daily-required nutrients directly from unprocessed foods. Articulate what can be accomplished by conventional breeding and what might require alternative approaches and advocate for open sharing of data and information regarding biofortification efforts.

5. The Plant Environment Metagenome - to facilitate our understanding of the "whole plant" with a view toward crop improvement and sustainability. The "whole plant" includes not only the plant itself, but the entire microecology of interacting microorganisms within and upon its surfaces, both within an agricultural cropping system and in a natural environment.

6. Development of Medicinal Plant-based Products - to advocate ethnobotanical and natural product research and development of useful plant compounds for human health, as well as to establish the means by which new products can be efficiently tested and brought to market.

7. Species Information for Sustainable Adaptation Capability to Climate Change - to explore/develop an approach toward facilitating natural and managed ecosystem adaptation (or ameliorating the effects resulting from) to changes in climate that are already taking place and to integrate existing plant interaction information into an ecosystem perspective for the development of effective and predictive models.

8. Developing Perennial Rice/Wheat/Maize - to promote a vision where possible for the conversion of current mega-crops to perennial forms to stabilize land use and inputs and to promote sustainability along with yield maintenance.

9. Sharing Information and Resources - to develop a position statement for facilitating the global free exchange of information, phenotype and genotype data, and resources (including germplasm) that are in the public domain for approval by the GPC membership.

Each topic area had a GPC Advocate who took the lead on developing a half page summary that would assist in the development of a comprehensive two-page proposal. One of the proposals, the Biofortification (Welch and Graham 2004), seemed to be a pressing problem specially for developing countries as Brazil, where marginal populations do not have access to sustainable production of suitable nutritious food. According to the 2012 Annual Letter from Bill Gates (http://www.gatesfoundation.org/who-we-are/ resources-and-media/annual-letters-list/annual-letter-2012), the world is experiencing an alarming situation when over one billion people - which is equivalent to $15 \%$ of the human population - are living in extreme poverty. And worse, poor and developing countries use a great percentage of their 
income with expenditure on food, which determines the low quality level of life (Figure 1).

For millions of extremely poor people living in slums in cities, the way as they try to get food is the most pressing daily concern. This is especially visible in some African countries. Considering that there is a high correlation between food and basic health, the lack of adequate nutrition is a key reason why poor children suffer from diseases or even die so often. In the first ten years of their life, poor nutrition obstructs the development of mental capacities and the psychomotor development, and this severely and irreversibly limits their ability to grow, learn, and become healthy. Then, eradicate the extreme poverty and hunger appears to be the first development goal for governments and institutions to seek solutions in promoting good health over a lifetime.

Nevertheless, a chronic deficiency of essential vitamins and minerals (micronutrients) in the basic diet, collectively known as 'hidden hunger' (HHI-PD), is estimated to reach two billion lives worldwide (Muthayyal et al. 2013). The main deficiencies are of iron, zinc, vitamin $\mathrm{A}$, iodine, and folate, but deficiencies of vitamin B12 and other B vitamins also commonly occur, and account for the major source of morbidity (increased susceptibility to disease) and mortality worldwide. These deficiencies affect particularly children, impairing their immune system and normal development, causing disease and ultimately death.

\section{STRATEGIES FOR BIOFORTIFICATION BASED ON PLANT SCIENCE}

Plants are the primarily supply for a high quality diet for humans. So, making use of a diverse diet rich in vegetables and fruits is undoubtedly the best way to avoid micronutrient deficiencies.

For the people who cannot afford a balanced diet, the use of nutrient-dense staple crops is a good alternative. We'll describe examples of how simple technologies can help to improve the nutritional feature of two crops. The first is about the sweet potatoes, that are available as varieties either rich or poor in provitamin A. The biofortified accumulating provitamin-A variety is orange-fleshed as opposed to the non-biofortified white-fleshed varieties. Introducing the biofortified varieties or providing new genetically improved varieties with high accumulating provitamin $\mathrm{A}$ is an advantageous strategy to enhance the nutritional quality for people living in remote rural areas.

As opposed to sweet potatoes, no natural provitamin-A is found naturally in rice varieties worldwide. In many countries in Asia, Latin America and Africa, where rice is in the basis of the eating pyramid, the absence of $\beta$-carotene reveal a pronounced occurrence of blindness and disease susceptibility. What is interesting is that rice plants synthesize provitamin A in most of the tissues, but not in the endosperm (as one knows, endosperm is the reserve tissue of the seed and also the edible part). Additionally, the outer layer of the

\section{The Poor Spend a High Percentage of Their Income on Food}

Average total

household expenditure

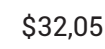

$\$ 32,05$

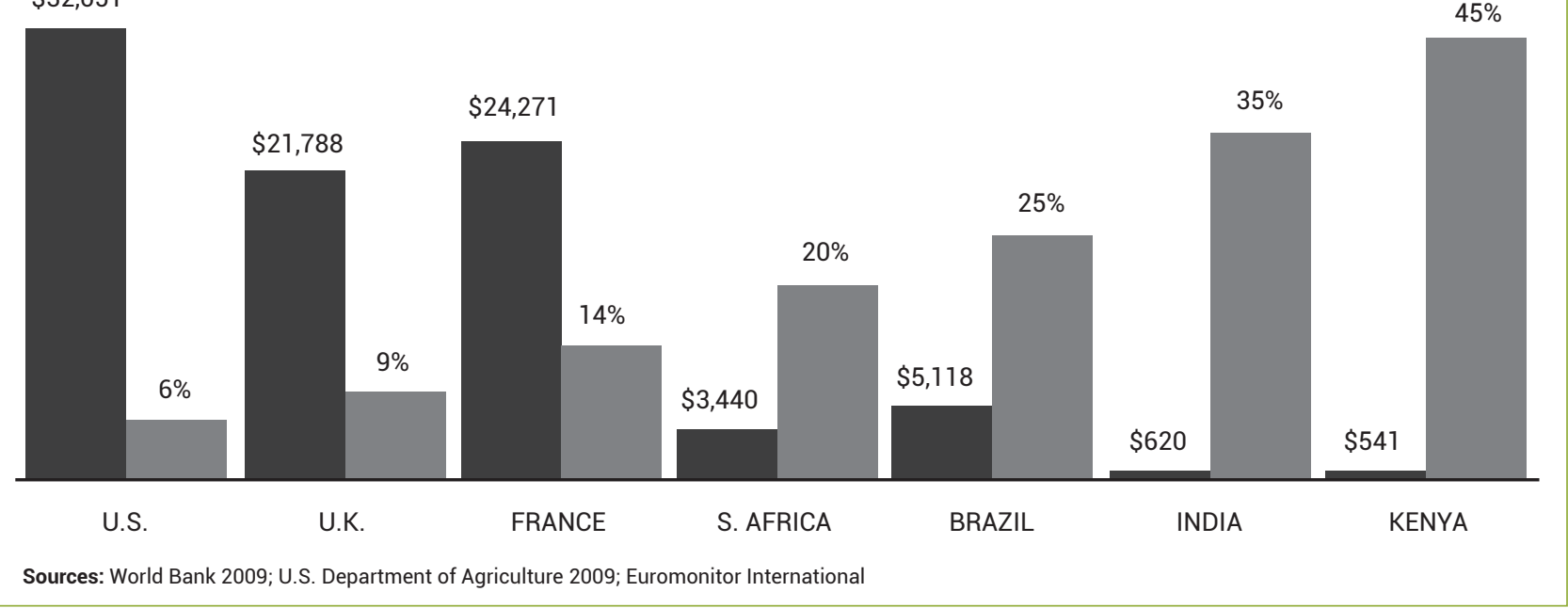

Figure 1. Average incomes for populations of several countries and percentage of food expenditure. Reproduction authorized by Bill and Melinda Gates Foundation. 
grains (aleurone layer), usually removed during the process of milling and polishing, contains a sort of nutrients including vitamin-B and lipids, but no provitamin-A. So, rice grains as usually consumed are nutritionally deficient in vitamin-A, iodine, iron, zinc, and is a major source of morbidity (increased susceptibility to disease) and children mortality worldwide.

The genes involved in the metabolic path for the provitamin A synthesis are present in the seed but they are not active during the seed development and maturation. For that reason, turning them on would be important since this would allow the synthesis of provitamin $\mathrm{A}$ in the endosperm. This simple thinking lead Ingo Potrykus (ETH Zurich) and Peter Beyer (Univ of Freiburg), who in a collaborative effort were able to show that production of $\beta$-carotene could be turned on in rice grains using a set of transgenes (Ye et al. 2000). The product of this research was commonly called as the Golden Rice. Yet to be officially accepted by international communities, the International Rice Research Institute (IRRI) along with the Phillippine Rice Research Institute (PhilRice) are requiring a permission to the regulatory authority in Philippines, and maybe some releases of the biofortified Golden Rice may occur to farmers on 2014.

\section{REFERENCES}

Chen H, Lin Y (2013) Promise and issues on genetically modified crops. Current Opinion in Plant Biology 16:255-260.

Davison J (2010) GM plants: Science, politics and EC regulations. Plant Science 178:94-98.

Fuglie KO, Wang SL, Ball VE (2012) Productivity growth in agriculture: An international perspective. In: Fuglie KO, Wang SL, Ball VE (Eds). Productivity growth in agriculture: an international perspective. Oxfordshire: CAB International.

Gruissem W, Lee C-H, Oliver M, Pogson B (2012) The global plant council: Increasing the impact of plant research to meet global challenges. Journal of Plant Biology 55:343-348

Habermann G (2012) Initiative plant research for a sustainable agriculture in the Neotropics. In: Book of abstracts of the $10^{\text {th }}$ International Congress on Plant Molecular Biology. Jeju, South Korea, p. 169.

Haridasan M (2008) Nutritional adaptations of native plants of the cerrado biome in acid soils. Brazilian Journal of Plant Physiology 20:183-195.

Hibberd JM, Sheehy JE, Langdale JA (2008) Using C4 photosynthesis to increase the yield of rice - rationale and feasibility. Current Opinion in Plant Biology 11:228-231.
And finally, we should look at some forgotten issues on agriculture. For reasons that are still poorly understood, some seeds and root crops are being underutilized by scientists and farmers. Coming these crops to light would inevitably bring nutritional and environmental benefits to humans and farmers in general. The list of potential crops are enormous including South American species (Chenopodium quinoa, Amaranthus caudatus, Eugenia uniflora, Euterpe oleraceae, hundreds of tuber species etc.). What we need to do is to assess strategies for the deployment of these crops for which future markets are realistic.

\section{ACKNOWLEDGMENTS}

We acknowledge the Fundação de Amparo à Pesquisa do Estado de São Paulo (FAPESP) for financial support (Proc. Fapesp 2012/01351-9) to Gustavo Habermann and Fundação Carlos Chagas Filho de Amparo à Pesquisa do Estado do Rio de Janeiro (FAPERJ) for financial support to Ricardo Bressan-Smith. We extend our acknowledgements to the Conselho Nacional de Desenvolvimento Científico e Tecnológico $(\mathrm{CNPq})$ for research productivity fellowships to Gustavo Habermann and Ricardo Bressan-Smith.

Hill J, Nelson E, Tilman D, Polasky S, Tiffany, D (2006) Environmental, economic, and energetic costs and benefits of biodiesel and ethanol biofuels. Proceedings of the National Academy of Sciences of the United States of America 103:11206-11210.

Horst WJ, Wang Y, Eticha D (2010) The role of the root apoplast in aluminium-induced inhibition of root elongation and in aluminium resistance of plants: a review. Annals of Botany 106:185-197.

Koning N, Lttersum MK van (2009) Will the world have enough to eat? Current Opinion in Environmental Sustainability 1:77-82.

Kopittke PM, Blamey FPC, Menzies NW (2008) Toxicities of soluble $\mathrm{Al}, \mathrm{Cu}$, and $\mathrm{La}$ include reputures to rhizodermal and root cortical cells of cowpea. Plant Soil 303:217-227.

Kush GS (2001) Green revolution: The way forward. Nature Reviews Genetics 2:815-822.

Lapola DM, Schaldach R, Alcamo J, Bondeau A, Koch J, Koelkinga C, Priess JA (2010) Indirect.

land-use changes can overcome carbon savings from biofuels in Brazil. Proceedings of the National Academy of Sciences of the United States of America 107:3388-3393. 
Leegood RC (2013) Strategies for engineering C4 photosynthesis. Journal of Plant Physiology 170:378-388.

Muthayya1 S, Rah JH, Sugimoto JD, Roos FF, Kraemer K, Black RE (2013) The Global Hidden Hunger Indices and Maps: An Advocacy Tool for Action. PLoS ONE 8:e67860.

Nogueira P (2013) Divisor de águas. Unesp Ciência 45:18-25.

Pfaffenzeller S, Newbold P, Rayner A (2007) A short note on updating the Grilli and Yang commodity price index. World Bank Economic Review 21:151-163.

Phalan B, Bertzky M, Butchart SHM, Donald PF, Scharlemann JPW, Stattersfield AJ, Balmford A (2013) Crop expansion and conservation priorities in Tropical countries. PLoS One 8:e51759.

Pinheiro MHO, Monteiro R (2010) Contribution to the discussions on the origin of the Cerrado biome: Brazilian savanna. Brazilian Journal of Biology 70:95-102.

Ratter JA, Ribeiro JF, Bridgewater S (1997) The Brazilian Cerrado vegetation and threats to its biodiversity. Annals of Botany $80: 223-230$
Sawyer D (2008) Climate change, biofuels and eco-social impacts in the Brazilian Amazon and Cerrado. Philosophical Transactions of the Royal Society B 363:1747-1752.

Souza MC, Habermann G (2012) Towards a new ecophysiological approach to understand citrus crop growth and yield mirroring in the Brazilian savanna genetic resources. In: Rahman IMM, Hasegawa H. Water Stress. Rijeka: Intech Open Acces Publisher. p. 151-164.

Taiz L (2013) Agriculture, plant physiology, and human population growth: past, present, and future. Theoretical and Experimental Plant Physiology 25:167-181.

Von Uexküll HR, Mutert E (1995) Global extent, development and economical impact of acid soils. Plant Soil 171:1-15.

Welch RM, Graham RD (2004) Breeding for micronutrients in staple food crops from a human nutrition perspective. Journal of Experimental Botany 55:353-364.

Ye X, Al-Babili S, Klöti A, Zhang J, Lucca P, Beyer P, Potrykus I (2000) Engineering the provitamin A ( $B$-caroten) biosynthetic pathway into (carotenoid-free) rice endosperm. Science 287:303-305 